\title{
Assessing Tradeoffs between Development and Conservation: A Case of Land Use Change in a National Park of Korea
}

\author{
Miju Kim ${ }^{1}\left(\right.$, Sangkwon Lee $^{2}$ and Chi-Ok $\mathrm{Oh}^{3, *}$ \\ 1 Graduate School of Environmental Studies, Seoul National University, Seoul 08826, Korea; mijukim@snu.ac.kr \\ 2 College of Arts, Sciences, Business and Education, Winston-Salem State University, \\ Winston-Salem, NC 27110, USA; lees@wssu.edu \\ 3 Graduate School of Culture, Chonnam National University, Gwangju 61186, Korea \\ * Correspondence: chiokoh@chonnam.ac.kr; Tel.: +82-62-530-4075
}

check for

updates

Citation: Kim, M.; Lee, S.; Oh, C.-O. Assessing Tradeoffs between Development and Conservation: A Case of Land Use Change in a National Park of Korea. Land 2021, 10 , 152. https://doi.org/10.3390/ land10020152

Received: 6 January 2021

Accepted: 30 January 2021

Published: 3 February 2021

Publisher's Note: MDPI stays neutral with regard to jurisdictional claims in published maps and institutional affiliations.

Copyright: (c) 2021 by the authors. Licensee MDPI, Basel, Switzerland. This article is an open access article distributed under the terms and conditions of the Creative Commons Attribution (CC BY) license (https:// creativecommons.org/licenses/by/ $4.0 /)$.

\begin{abstract}
Protected areas are places that provide diverse ecosystem services, including cultural ecosystem services. At the same time, the development and unbalanced use of natural resources in protected areas often create environmental threats and social conflicts. This study estimates the economic value of environmental consequences derived from the construction of an airport in a national park in Korea. We employ a discrete choice experiment to assess economic values and consider a key part of the tradeoffs derived from the airport construction at Heuksan Island of Dadohae Marine National Park in Korea. The results show that social benefits related to improved accessibility and tourism opportunities would be generated but at substantial costs resulting from environmental degradation and the reduction in bird populations. A segmentation analysis also reveals that heterogeneous preferences exist based on variables reflecting individuals' visit experiences and trust in the government. The findings indicate that considering environmental impacts is important when evaluating the feasibility of a development project in a protected area.
\end{abstract}

Keywords: conservation; development; protected areas; national park; nonmarket valuation; discrete choice experiment

\section{Introduction}

The choice between conserving and developing protected areas is a critical issue in environmental management. Protected areas such as national parks and reserves have been designated not only to conserve nature but also to provide environmental benefits that enhance the quality of life in that community [1]. A good balance between nature conservation and human use enables sustainable ecosystem functions that benefit both nature and humans. However, decision makers often need to choose between conservation and development. While acknowledging the importance of conservation, many people maintain that developing protected areas can bring economic benefits to a community and can alleviate poverty [2]. On the other hand, human activities have led to environmental degradation and threats [3] and the designation of protected areas is often regarded as an important instrument for protecting biodiversity and habitats $[4,5]$.

The tradeoffs in the choice between conservation and development influence public policy decision making [6]. The tradeoff concept is closely tied to the principle of opportunity costs [7]. Thus, it is important to consider the opportunity costs of policy alternatives and to identify the project that is most beneficial to the public. Selecting the best alternative requires a comprehensive assessment of the resources involved [8]. In the context of environmental resource management, assessing the benefits and costs associated with natural resources is crucial for project adoption and implementation. In particular, natural resources and the environment are public (or common) goods, implying that it is difficult to estimate the economic value of nonmarket goods, including their use value and nonuse value. 
Several economic valuation approaches have been employed to assess the value of natural resources. Economic valuation methods convert the environmental value of natural resources to monetary terms, enabling a cost-benefit analysis of a particular project or policy [9]. While the economic benefits accruing from development projects, typically measured with economic impacts (i.e., direct and indirect effects) through an increase in the number of visitors, are relatively easy to express in monetary terms, economic costs such as environmental degradation caused by development projects are more complex. Thus, nonmarket valuation methods are typically used to assess the economic value of a change in environmental quality because most environmental goods and services are not traded in the market [10].

Studies have examined the diverse issues related to conservation and development of protected areas, including the relationship between protected areas and quality of life, the role of protected areas in terms of ecological value and biodiversity, and the economic value of protected areas [8,11-13]. Most studies have concluded that tradeoffs between biological conservation and economic well-being are inevitable [14,15]. Promoting the development of protected areas may reduce their geographical size or weaken their governance due to the intensification of human activities, as shown in many cases presented by studies on protected area downgrading, downsizing, and degazettement (PADDD) [16,17]. There have been 3749 PADDD events globally over the past 100 years [18], including those that cause land use and land cover (LULC) changes.

An exemplary case of a potential PADDD event occurs in Korea, involving the planned construction of a small airport on an island, located in a national park. The construction of an airport in the Heuksando area is expected to cause the transformation of land use and social conflicts due to its environmental and economic effects. Local elected officials, developers, and some residents have been advocating for the plan since it was proposed in 2002. After tempering regulations in 2010 and 2011, the plan was supported in a preliminary feasibility study in 2013 [19], in which most of the nonmarket services associated with environmental degradation were not included in the cost-benefit analysis. From the local point of view, a large amount of public money, especially public subsidies from the central government, will flow into the region and ultimately contribute to economic growth through the multiplier effect. The airport will also facilitate tourist access to the region by providing more transportation alternatives. The increased tourist spending will contribute to the local economy. However, the airport construction plan has triggered debates on economic-oriented development frameworks against conservation-oriented ones. It is still a hot issue even after the National Parks Committee withheld the plan to protect migratory birds in 2016. While national parks bring economic benefits, the ecosystems they provide can be devastated by the economic activities associated with the various development practices that take place in national parks [20].

This study intends to assess the economic values that individuals place on social and environment consequences derived from the construction of a new airport in Heuksando, Korea. We employed a discrete choice experiment (DCE) as a suitable method, which enables researchers to examine individuals' preferences by determining the relative importance of different attributes [21]. In the following sections, we review the literature on national parks in Korea and estimate the economic value of environmental goods and services. Then, we describe the study's method of analysis and findings. Finally, we discuss the findings' implications for environmental effects and economic development.

\section{Literature Review}

\subsection{LULC Changes in National Parks in Korea}

National parks in Korea are referred to as regions worthy of representing natural ecosystems and cultural environments. While a total of 22 national parks-mainly mountainous parks, along with four marine and coastal parks-occupy only about $4 \%$ of Korea's land mass, they provide habitats for many species, including $45 \%$ of Korea's recorded species and $65 \%$ of its endangered species [22]. 
Despite the importance of its biodiversity, development projects accompanied by LULC changes have been continuously proposed and approved of in national parks by central and local governments, such as adding golf courses, ski resorts, pumped storage power plants, cable cars, and high-speed railway tunnels. A concern related to these developments inevitably arises because of environmental degradation and social conflicts [23,24]. Kim et al. [25] analyzed newspaper editorials on national parks and found that the development of tourism facilities was a major issue concerning national park management from 1990 to 2012, and one example is an installation of cable cars in Seorak National Park. Chang [23] examined social conflicts due to new cable car installations among diverse stakeholders. The results showed that the local government and some residents were in favor of the project because it could help attract tourists. However, the Ministry of Environment, environmental nongovernmental organizations, and other residents opposed the project due to concerns about environmental degradation [23].

Social conflicts often become serious due to the lack of principles and the legal system for natural resource management despite the fact that related laws have existed since 1967 [26]. The National Park Committee does not have enough power to reject to the central government's position [26]. As a result, when there are conflicts among departments of the central government, a final decision may depend on the president, who can either allow or prohibit the proposed plan by easing or tightening environmental regulations by a presidential decree. According to Hwang and Park [27], the government is more likely to alter environmental regulations when economic development has high priority as a government objective. When environmental degradation is expected as a result of development projects, it is not easy to assess the economic value of degradation. Furthermore, the lack of consistency in policy decision making processes negatively influences public trust in the government. In fact, the government's performance on environmental problems over the past decades is one of the factors significantly affecting public trust in Korea's central government [28]. Given this, a measure of public trust in the government's environmental policies was employed as one of the segmentation variables. The following section explains how to assess the economic value of environmental resources such as protected areas.

\subsection{Economic Value of Environmental Resources}

Nonmarket valuation methods are commonly employed to assess the economic value of public goods, including tangible use value and intangible nonuse value. Stated preference methods such as the contingent valuation method (CVM) and discrete choice experiment (DCE) are used to estimate the value of nonmarket goods by using consumers' stated behaviors in a hypothetical setting. The CVM asks respondents to choose whether they would be willing to pay a certain amount to realize a targeted level of nonmarket goods [9]. The DCE, an alternative to the CVM, is an application of the characteristics theory of value combined with the random utility theory [29]. The DCE typically employs multiple choice sets, each containing a set of hypothetical alternatives from which respondents are asked to choose their preferred alternative in a choice set. The alternatives are described in terms of a set of attributes, with each attribute comprising two or more levels [30]. Thus, the DCE provides information on the amount that individuals would pay for an improvement in an attribute level or the compensation that they would require if an attribute level declines [31]. The DCE has several advantages over other stated preference methods such as the CVM. The DCE can capture more respondent information by manipulating multiple attributes and attribute levels to create various new goods; it can also provide a more profound understanding of the relative importance of attributes when there are tradeoffs among the attributes [32].

The DCE has been employed extensively to estimate the economic values of forest conservation and protection [33,34], park management [35,36], wetlands [37], coastal resources and marine conservation zones [38,39], and biodiversity conservation [40]. Furthermore, several DCE studies have used a segmentation approach and subsequently divided respon- 
dents into subgroups based on the type of outdoor recreation [36], geographic regions [38], and tourists and residents [39].

Overall, the magnitude of the tradeoffs between environmental conservation and economic development needs to be carefully reflected upon when establishing public policy. Although there have been diverse DEC studies, to the authors' knowledge, there is a paucity of studies that have directly dealt with the issue of development versus conservation. This paper expectedly provides comprehensive information on the tradeoff relationships involved in development projects in national parks.

\section{Methods}

\subsection{Study Site}

Heuksando, where Heuksan Airport is to be constructed, is part of the Dadohae Marine National Park (DMNP) (see Figure 1). The DMNP is the largest national park in Korea, with a total area of $2266 \mathrm{~km}^{2}\left(1975 \mathrm{~km}^{2}\right.$ of sea area and $291 \mathrm{~km}^{2}$ of land area) and is spread widely from Hongdo of Sinan County to the Dolsan area of Yeosu city. The DMNP contains about 400 islands and is divided into eight park districts, including the Heuksando and Hongdo district. The DMNP attracts about 550,000 visitors per year, and the Heuksando and Hongdo district is known as a main tourist attraction in the DMNP [41]. This area is part of the East Asian-Australasian Flyway, where it serves as a stopover and wintering site for sea-crossing migratory birds and a habitat for resident birds [42-44].

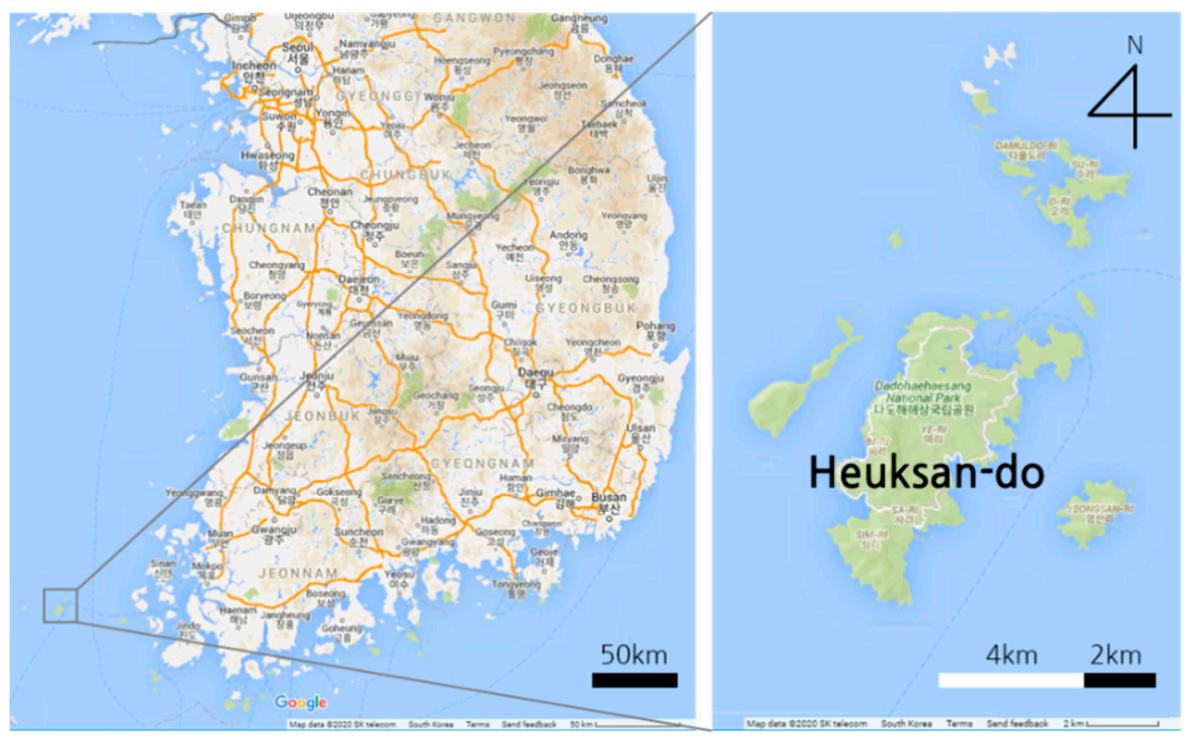

Figure 1. Location and map of the study area, Heuksando, Korea.

Heuksando is a key island in the Heuksando and Hongdo district of the DMNP and belongs administratively to the Heuksan-myeon area of Sinan County in South Jeolla Province. Heuksando is situated $92.7 \mathrm{~km}$ away from the mainland, and multiple islands including Hongdo, Damundo, and Daedundo along with Heuksando constitute the Heuksan archipelago. Heuksando has an area of $19.7 \mathrm{~km}^{2}$ and a population of 4494 as of 2016 [45]. Heuksando is famous for its landscapes, cruise ship tours, and seafood. According to a report by the Korea Development Institute (KDI) [19], about 426,000 tourists visited Heuksando every year during the 2000s.

\subsection{Data Collection}

We collected the data through an online survey using a panel recruited by an online survey company (Embrain.co.kr located in Seoul) between November and December 2017. The survey used a quota sampling strategy in proportion to the population of each metropolitan area to ensure the selection of a nationally representative sample with respect 
to all geographical areas of residence. The study population was confined to individuals who had visited at least one national park over the previous five years, as the questionnaire included many national park-related policy and management questions. The number of visitors to the national parks amounted to 47 million as of 2017 [22], and the population of South Korea was about 51 million [46]. Although the study sample is not likely to represent the entire population, we expect that almost all of the Korean people have visited a national park at least once during the previous five years. A total of 12,839 invitations were sent out, and 2200 individuals were willing to participate in the survey. Among them, 1090 were not qualified due to age, gender, and region quotas and another 158 did not complete the survey. The survey was closed after 1000 individuals completed the questionnaire.

\subsection{Discrete Choice Experiment}

The DCE, as a stated preference method, uses hypothetical scenarios to elicit public responses regarding the relative importance of given attributes. To develop the attributes and levels for the DCE, we used an extensive literature review, including a preliminary feasibility report [19] and an environment impact assessment report [47], which were key papers that reflected accumulated social discussions. The social benefits of the airport construction include reduced travel time due to improved accessibility for residents and tourists, and enhanced economic impact of tourism. The KDI report [19] indicated that a new airport expectedly reduces travel time between Seoul and Heuksando from seven hours to less than three and optimistically increases the number of visitors to 1,364,000. However, the report was also criticized due to its overestimation of the demand and the omission of environmental consequences. Many environmental concerns related to the airport construction were also addressed, including damage to trees and coasts and the threat of bird habitat destruction in the island. The environment impact assessment [47], which was conducted afterwards, claimed that the airport construction would remove about 120,000 trees, 41 hectares of forests, and 13 hectares of coast, which would seriously affect birds and their habitats in Heuksando.

The following five attributes and levels were identified: (1) degradation in forest and marine environments (ENV), (2) reduction in the number of birds (BIRD), (3) improvement in accessibility (ACCESS), (4) additional tourism opportunities (TOUR), and (5) household income tax (TAX). The first two attributes are associated with environmental concerns (ENV and BIRD) derived from the airport construction, and two others are related to the social benefits (ACCESS and TOUR) associated with it. The attribute ENV indicates the degradation in forests and marine environments in the airport areas planned, and the attribute BIRD refers to the reduction in habitats and the population of birds. The ACCESS attribute indicates the improvement in accessibility for residents and tourists, and the TOUR attribute specifies the availability of local amenities and tourism activities. Finally, the attribute TAX indicates the annual additional household income tax charged for the next 10 years. The levels used for each attribute were also carefully selected to represent the conditions of either a new airport or no airport and are presented in Table 1. A low level is the condition when the airport is not constructed, and medium and high levels represent viable conditions when the airport is built. We evaluated the social and environmental impacts of the airport construction by asking the respondents to read the instructions (see Appendix A) before answering the DCE questions. 
Table 1. Explanation of the attributes and levels.

\begin{tabular}{|c|c|c|}
\hline Variables & Explanation & Levels \\
\hline ENV & $\begin{array}{l}\text { Degradation in forests and coastal } \\
\text { environments in the planned airport area }\end{array}$ & $\begin{array}{l}\text { Low: No damage } \\
\text { Medium: Estimated damage to the forests and coastal } \\
\text { environments of about } 20 \text { and } 10 \text { soccer fields, respectively } \\
\text { High: Estimated damage to the forests and coastal environments of } \\
\text { about } 40 \text { and } 20 \text { soccer fields, respectively }\end{array}$ \\
\hline BIRD & $\begin{array}{l}\text { Reduction in habitats and population of } \\
\text { birds due to the airport construction }\end{array}$ & $\begin{array}{l}\text { Low: No damage to bird habitats and no change in the bird } \\
\text { population } \\
\text { Medium: } 5 \% \text { decline in bird habitats and } 15 \% \text { decrease in the total } \\
\text { bird population } \\
\text { High: } 10 \% \text { decline in bird habitats and } 30 \% \text { decrease in the total } \\
\text { bird population }\end{array}$ \\
\hline ACCESS & $\begin{array}{l}\text { Improvement in accessibility for } \\
\text { residents and tourists }\end{array}$ & $\begin{array}{l}\text { Low: several transportation means required, and the travel time is } \\
\text { quite long (e.g., from the center of Seoul to Heuksando, about } 7 \mathrm{~h} \text { ) } \\
\text { High: travel by air, and the travel time is relatively short (e.g., from } \\
\text { the center of Seoul to Heuksando, about } 3 \mathrm{~h} \text { ) }\end{array}$ \\
\hline TOUR & $\begin{array}{c}\text { Availability of local amenities and } \\
\text { tourism activities }\end{array}$ & $\begin{array}{l}\text { Low: limited accommodations and restaurants scattered on the } \\
\text { island and few tourism activities available } \\
\text { Medium: some accommodations and restaurants located on the } \\
\text { island; some tourism amenities and tourism activities available } \\
\text { High: a variety of accommodations and restaurants located in the } \\
\text { island and diverse tourism amenities (e.g., information centers, } \\
\text { trails, and museums) and tourism activities (e.g., walk } \\
\text { and fishing) available }\end{array}$ \\
\hline TAX & $\begin{array}{l}\text { The annual additional household income } \\
\text { tax for next } 10 \text { years }\end{array}$ & KRW 1000 (USD 0.94), 3000 (2.81), 5000 (4.69), 10,000 (9.37) \\
\hline
\end{tabular}

The number of combinations of choice sets from the five attributes with two to four levels is substantial. Thus, to ensure that each respondent answered a manageable number of choice sets, a fractional factorial design suggested by Kuhfeld [48] was employed using SAS ${ }^{9} 9.3$, which generated 36 choice sets. A blocking tool was used to divide the 36 choice sets into nine versions. Therefore, each version of the questionnaire contained four choice sets. Figure 2 shows an example of the choice sets used in the questionnaire, which consist of two alternatives and a no-choice option.

The DCE has often been used to assess economic values in the field of natural resource management because it reflects individuals' tradeoff-oriented preferences. The DCE is based on utility maximization theory and random utility theory. Utility maximization theory suggests that individuals try to maximize their utility (or benefits) by making better choices [49]. While each choice alternative (or product or service) consists of numerous attributes, it is known that individuals commonly make decisions based on a small number of key attributes that are most interesting to them. Thus, the five attributes described above were selected for this study. Random utility theory posits that utility is composed of a measurable (or systematic) section of utility using the five attributes included in the choice sets and a random error component reflecting other attributes not included in the study (i.e., uncertainty factors). Thus, the utility of choice alternative $\mathrm{j}$ can be represented as

$$
\mathrm{U}_{\mathrm{j}}=\mathrm{V}_{\mathrm{j}}(X)+\varepsilon_{\mathrm{j}}=X_{\mathrm{j}} \beta+\varepsilon_{\mathrm{j}}
$$

where $V_{j}$ is the measurable section of utility and $\varepsilon_{j}$ is the random error component of utility. Furthermore, $X_{j}$ is the vector of the attributes, and $\beta$ is the coefficient vector to be estimated. Because the random error component is not observable to researchers, $a$ statistical assumption is required for model estimation. Typically, assuming the error 
terms are independently and identically distributed with the extreme value distribution, a condition logit $(C L)$ model can be used to estimate $U_{j}[50,51]$.

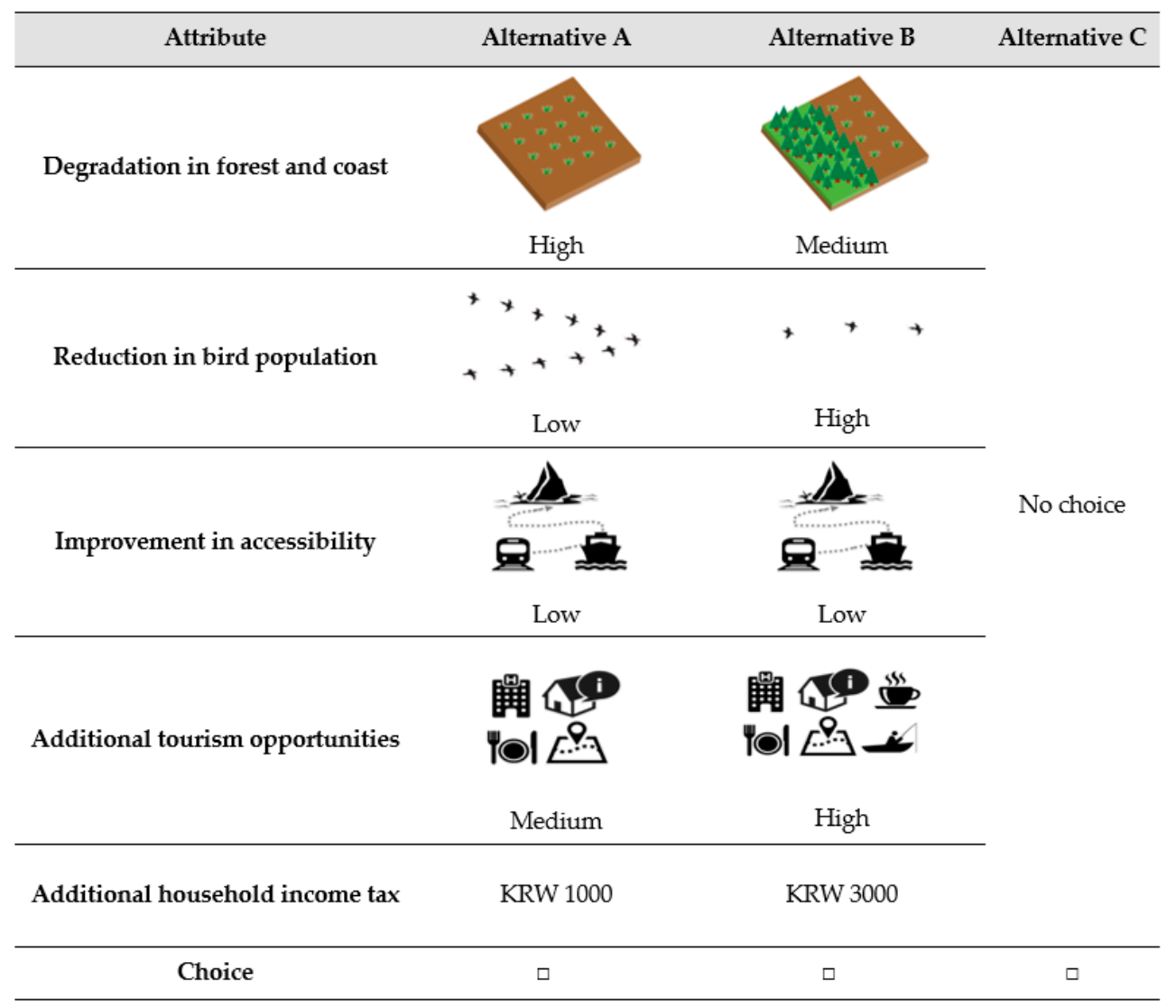

Figure 2. Example of a choice set.

A CL model can provide only a single set of parameter coefficients for the attributes. This means that the CL's estimation results represent the preferences of an average individual. However, it is more realistic to assume that there is no average individual and that substantial preference heterogeneity prevails. Consequently, a random parameter logit (RPL) model takes into account unobserved heterogeneity in the systematic section of the model by letting the coefficients vary randomly over individuals and thus overcomes the CL model's constraint [52]. This study's RPL model was employed using NLogit $5.0^{\circledR}$.

\section{Results}

\subsection{Descriptive Statistics of Sociodemographics}

The descriptive statistics of the samples derived from the survey are shown in Table 2. The final data used for analysis included 1000 respondents. The mean age was 42.5 , and about half the respondents were male (51\%). Less than one-fourth of the respondents had previously visited Heuksando (23\%), and 23\% had a household monthly income of KRW 6 million (about USD 5623$)^{1}$ or above. About $66 \%$ had a bachelor's degree or postgraduate education. Respondents' trust in the government's environmental policies was evaluated using 12 fivepoint scale items proposed by Grimmelikhuijsen and Knies [53] (see Appendix B), and the exploratory factor analysis indicated the existence of a single factor. After aggregating these items, a discrete variable, TRUST, was created with a relatively low mean score of 2.79. 
Table 2. Descriptive statistics of explanatory variables.

\begin{tabular}{clc}
\hline Variable & \multicolumn{1}{c}{ Description } & \% or Mean \\
\hline GENDER & A respondent's gender & \\
& Male & $51.0 \%$ \\
& Female & $49.0 \%$ \\
AGE & Respondent age (year) & $42.49(12.16)$ \\
& Level of a respondent's education (year) & \\
& High school graduation or less (0-12) & $13.8 \%$ \\
& Some college education (13-15) & $20.5 \%$ \\
INCOME & Bachelor's degree or higher (>16) & $65.7 \%$ \\
& Respondent's income & \\
& $\quad$ KRW 1 million & $2.6 \%$ \\
& KRW 1 million-2 million & $5.7 \%$ \\
& KRW 2 million-3 million & $15.2 \%$ \\
& KRW 3 million-4 million & $18.4 \%$ \\
& KRW 4 million-5 million & $20.0 \%$ \\
& KRW 5 million-6 million & $14.8 \%$ \\
& $>$ KRW 6 million & $23.3 \%$ \\
VISIT & Previous visit to Heuksando (1 = yes, 0 = no) & $22.8 \%$ \\
& A respondent's trust in the government's & \\
TRUST & environmental policies (coded 1 to 5, 1 = very & $2.79(0.81)$ \\
& unlikely, 5 = very likely) & \\
\hline
\end{tabular}

${ }^{1}$ Parentheses indicate standard deviation.

\subsection{Estimation Results: An Aggregate Model}

The results of the random parameter logit model with 500 Halton draws are shown in Table 3. A normal distribution for each coefficient besides TAX was assumed in the estimation. The goodness-of-fit measure evaluated with McFadden's $\rho^{2}$ was 0.161. An alternative specific constant (ASC) was inserted into the model to assess the effects of the attributes that were not included in the utility function. A positive ASC coefficient suggested that the respondents preferred to choose the proposed alternatives to none of the alternatives provided. We inserted the respondents' visit experience and trust in the government's environmental policies as interaction terms to see their effects. Dummy coding was used for each attribute. The effect of each attribute level was shown by the parameter coefficient, and the other level (i.e., low level) not included in the estimation was used as the base. For example, the additional tourism opportunities attribute had three levels and two dummy coded variables were estimated using the other level as the base.

All attribute coefficients were statistically significant with a priori expected signs. The negative coefficients of ENV indicate that the respondents preferred the low level over the medium or high level, suggesting that they did not want environmental degradation caused by the airport construction. Likewise, the negative coefficients of BIRD suggest that the respondents did not want to see the number of birds reduced due to the new airport. Contrariwise, the positive coefficient of ACCESS indicates that the respondents preferred improved accessibility to the Heuksando area. The positive coefficients of TOUR suggest that the provision of expanded tourism opportunities in the area due to the airport construction would help increase the respondents' utility. Finally, the negative coefficient of TAX confirms that the respondents did not prefer increases in income tax, as expected. 
Table 3. Results of the random parameter model (aggregate model).

\begin{tabular}{|c|c|c|c|c|c|}
\hline Attribute & Level & Coefficient & Std. Err & $\begin{array}{c}\text { SD of } \\
\text { Coefficient }\end{array}$ & MWTP (KRW) \\
\hline \multirow{2}{*}{$\begin{array}{c}\text { Degradation in forest and marine } \\
\text { environments (ENV) }\end{array}$} & Medium & $-0.6506^{* * *}$ & 0.128 & $1.7769^{* * *}$ & -1796 \\
\hline & High & $-1.7285^{* * *}$ & 0.154 & $1.7769^{* * *}$ & -4772 \\
\hline \multirow{2}{*}{ Reduction in the number of birds (BIRD) } & Medium & $-0.4997^{* * *}$ & 0.130 & $1.9065^{* * *}$ & -1380 \\
\hline & High & $-0.9129^{* * *}$ & 0.131 & $1.6088^{* * *}$ & -2520 \\
\hline Improvement in accessibility (ACCESS) & High & $0.2318 *$ & 0.125 & $2.2399 * * *$ & 640 \\
\hline \multirow{2}{*}{ Additional tourism opportunities (TOUR) } & Medium & $0.4873^{* * *}$ & 0.135 & $2.1666^{* * *}$ & 1345 \\
\hline & High & $0.7122 * * *$ & 0.127 & $1.9564^{* * *}$ & 1966 \\
\hline $\mathrm{TAX}^{1}$ & & $-0.3622 * * *$ & 0.023 & & \\
\hline $\mathrm{ASC}^{2}$ & & $0.6339 * * *$ & 0.285 & & \\
\hline Visit $\times$ ASC & & $0.7982 * * *$ & 0.183 & & \\
\hline Trust $\times$ ASC & & $0.4818^{* * *}$ & 0.092 & & \\
\hline $\mathrm{N}$ & & \multicolumn{4}{|c|}{4000} \\
\hline Log Likelihood & & \multicolumn{4}{|c|}{-3685.27} \\
\hline McFadden $\rho^{2}$ & & \multicolumn{4}{|c|}{0.161} \\
\hline
\end{tabular}

Significance levels of 0.1 and 0.01 are represented by ${ }^{*}$ and ${ }^{* * *}$, respectively. ${ }^{1}$ Tax $/ 1000 .{ }^{2}$ The alternative specific constant (ASC) is coded 1 for alternative $\mathrm{A}$ and alternative $\mathrm{B}$ and 0 for neither alternative. ${ }^{3} \mathrm{SD}$ means standard deviation.

Instead of fixing the parameter coefficients at the mean, we allowed them to vary over each respondent. This specification can be represented as standard deviations of the coefficients in the RPL model [52]. All of the standard deviations of the coefficients were significant, suggesting that incorporating individual heterogeneity was beneficial. Moreover, the standard deviations of the coefficients were relatively greater than the coefficients, indicating that some respondents were likely to express different preferences with opposite signs of the coefficients [37].

To convert the respondents' preferences for changes in each attribute to monetary value, marginal willingness-to-pay (MWTP) per household per year was calculated by dividing each coefficient by the coefficient of income tax. These are reported in Table 3. Obviously, larger MWTPs indicate respondents' greater preference for that option relative to the base level. With all other attributes remaining the same (i.e., ceteris paribus), the MWTPs of the medium and high levels of ENV were KRW - 1796 (USD -1.68) and KRW -4722 (USD -4.47), respectively. Negative MWTPs mean that the respondents' benefits would diminish due to the airport construction. The MWTPs of BIRD were KRW -1380 (USD -1.29) and KRW - 2520 (USD -2.36) for the medium and high levels, respectively. On the other hand, the respondents would gain benefits of KRW 640 (USD 0.60) related to improved accessibility (ACCESS) to Heuksando and benefits of KRW 1345 (USD 1.26) and KRW 1966 (USD 1.84) via medium and high levels of additional tourism opportunities (TOUR) due to the new airport.

\subsection{Estimation Results: Segmented Model}

Among the interaction effects included in the aggregate model, VISIT and TRUST were statistically significant, implying that there were significant group differences. Consequently, these two variables were used to segment the respondents into two subgroups. We used VISIT to group the 228 respondents who had visited the Heuksando area and the rest (772) who had not. Most coefficients were significant with the expected signs, but the coefficient ACCESS was not significant for either model (Table 4). Furthermore, a difference was detected in the coefficients of the medium level of ENV. This coefficient for the group with visit experience was not significant. 
Table 4. Results of the random parameter model and the marginal willingness-to-pay (MWTP) of segmented groups (visit experience).

\begin{tabular}{|c|c|c|c|c|c|}
\hline \multirow{2}{*}{ Attribute } & \multirow{2}{*}{ Level } & \multicolumn{2}{|c|}{ Visit $=$ Yes } & \multicolumn{2}{|c|}{ Visit $=$ No } \\
\hline & & Coefficient & MWTP (KRW) & Coefficient & MWTP (KRW) \\
\hline \multirow{2}{*}{$\begin{array}{l}\text { Degradation in forest and marine } \\
\text { environments (ENV) }\end{array}$} & Medium & $\begin{array}{c}-0.3505 \\
(0.228)\end{array}$ & $\begin{array}{c}-1026^{\text {N.S. }} \\
(662)\end{array}$ & $\begin{array}{c}-0.7274^{* * *} \\
(0.153)\end{array}$ & $\begin{array}{l}-1958 \\
(419)\end{array}$ \\
\hline & High & $\begin{array}{c}-1.0505^{* * *} \\
(0.255)\end{array}$ & $\begin{array}{l}-3075 \\
(719)\end{array}$ & $\begin{array}{l}-1.9952^{* * *} \\
(0.189)\end{array}$ & $\begin{array}{l}-5371 \\
(496)\end{array}$ \\
\hline \multirow{2}{*}{$\begin{array}{l}\text { Reduction in the number of birds } \\
\text { (BIRD) }\end{array}$} & Medium & $\begin{array}{c}-0.6961 \text { *** } \\
(0.247)\end{array}$ & $\begin{array}{l}-2038 \\
(702)\end{array}$ & $\begin{array}{c}-0.4385^{* * *} \\
(0.160)\end{array}$ & $\begin{array}{l}-1180 \\
(431)\end{array}$ \\
\hline & High & $\begin{array}{c}-0.9206^{* * *} \\
(0.223)\end{array}$ & $\begin{array}{l}-2695 \\
(653)\end{array}$ & $\begin{array}{c}-0.9230 * * * \\
(0.161)\end{array}$ & $\begin{array}{l}-2485 \\
(432)\end{array}$ \\
\hline Improvement in accessibility (ACCESS) & High & $\begin{array}{l}0.3667 \\
(0.227)\end{array}$ & $\begin{array}{c}1074^{\text {N.S. }} \\
(657)\end{array}$ & $\begin{array}{l}0.1968 \\
(0.147)\end{array}$ & $\begin{array}{c}530^{\text {N.S. }} \\
(396)\end{array}$ \\
\hline \multirow{2}{*}{$\begin{array}{l}\text { Additional tourism opportunities } \\
\text { (TOUR) }\end{array}$} & Medium & $\begin{array}{c}0.7381^{* * *} \\
(0.263)\end{array}$ & $\begin{array}{l}2161 \\
(757)\end{array}$ & $\begin{array}{c}0.4095^{* * *} \\
(0.155)\end{array}$ & $\begin{array}{l}1102 \\
(418)\end{array}$ \\
\hline & High & $\begin{array}{c}0.9551^{* * *} \\
(0.246)\end{array}$ & $\begin{array}{l}2796 \\
(696)\end{array}$ & $\begin{array}{c}0.6036^{* * *} \\
(0.147)\end{array}$ & $\begin{array}{l}1625 \\
(395)\end{array}$ \\
\hline \multicolumn{2}{|l|}{ TAX $^{1}$} & $\begin{array}{c}-0.3416^{* * *} \\
(0.042)\end{array}$ & & $\begin{array}{c}-0.3715^{* * *} \\
(0.027)\end{array}$ & \\
\hline $\mathrm{ASC}^{2}$ & & $\begin{array}{c}2.3275^{* * *} \\
(0.347)\end{array}$ & & $\begin{array}{c}2.0541^{* * *} \\
(0.199)\end{array}$ & \\
\hline \multicolumn{2}{|l|}{$\mathrm{N}$} & \multicolumn{2}{|c|}{912} & \multicolumn{2}{|c|}{3088} \\
\hline Log Likelihood & & \multicolumn{2}{|c|}{-851.77} & \multicolumn{2}{|c|}{-2831.95} \\
\hline McFadden $\rho^{2}$ & & \multicolumn{2}{|c|}{0.150} & \multicolumn{2}{|c|}{0.165} \\
\hline
\end{tabular}

Note: Significance level of 0.01 is represented by ${ }^{* * *}$. Standard errors in parentheses. N.S. $=$ nonsignificant coefficients. ${ }^{1}$ Tax $/ 1000 .{ }^{2}$ The alternative specific constant (ASC) is coded 1 for alternative A and alternative B and 0 for neither alternative.

To compare the coefficient magnitudes between the groups, MWTPs were calculated, shown in Table 4. The delta method [54] was employed to generate standard errors. A standard hypothesis test (i.e., independent samples t-test) was employed to test the hypothesis of MWTP inequality between the two groups. Besides the nonsignificant coefficients that were excluded for comparison, all of the MWTPs were significantly different at the 0.01 level, denoting a high degree of preference heterogeneity. In general, the respondents who had not visited the Heuksando area were likely to be more concerned about the negative environmental impacts of the airport construction (i.e., ENV and BIRD) and to be less interested in additional tourism opportunities, as their MWTPs were lower than those of the respondents who had visited the area.

Next, 473 respondents were placed in the high-TRUST group and 527 were placed in the low-TRUST group based on the mean score of 2.79. The statistical significance levels and coefficient signs in Table 5 were identical, except for the ACCESS attribute, which was not significant for the high-TRUST group. The equality of the MWTPs was also tested (Table 5). All of the MWTPs were significantly different between the two groups, except for the coefficient of ACCESS, which was not significant. These results indicate a high degree of preference dissimilarity. Overall, the high-TRUST group was likely to be more concerned about environmental damage caused by the airport construction (i.e., ENV and BIRD) and less interested in its economic benefits (i.e., ACCESS and TOUR). 
Table 5. Results of the random parameter logit model (trust in government).

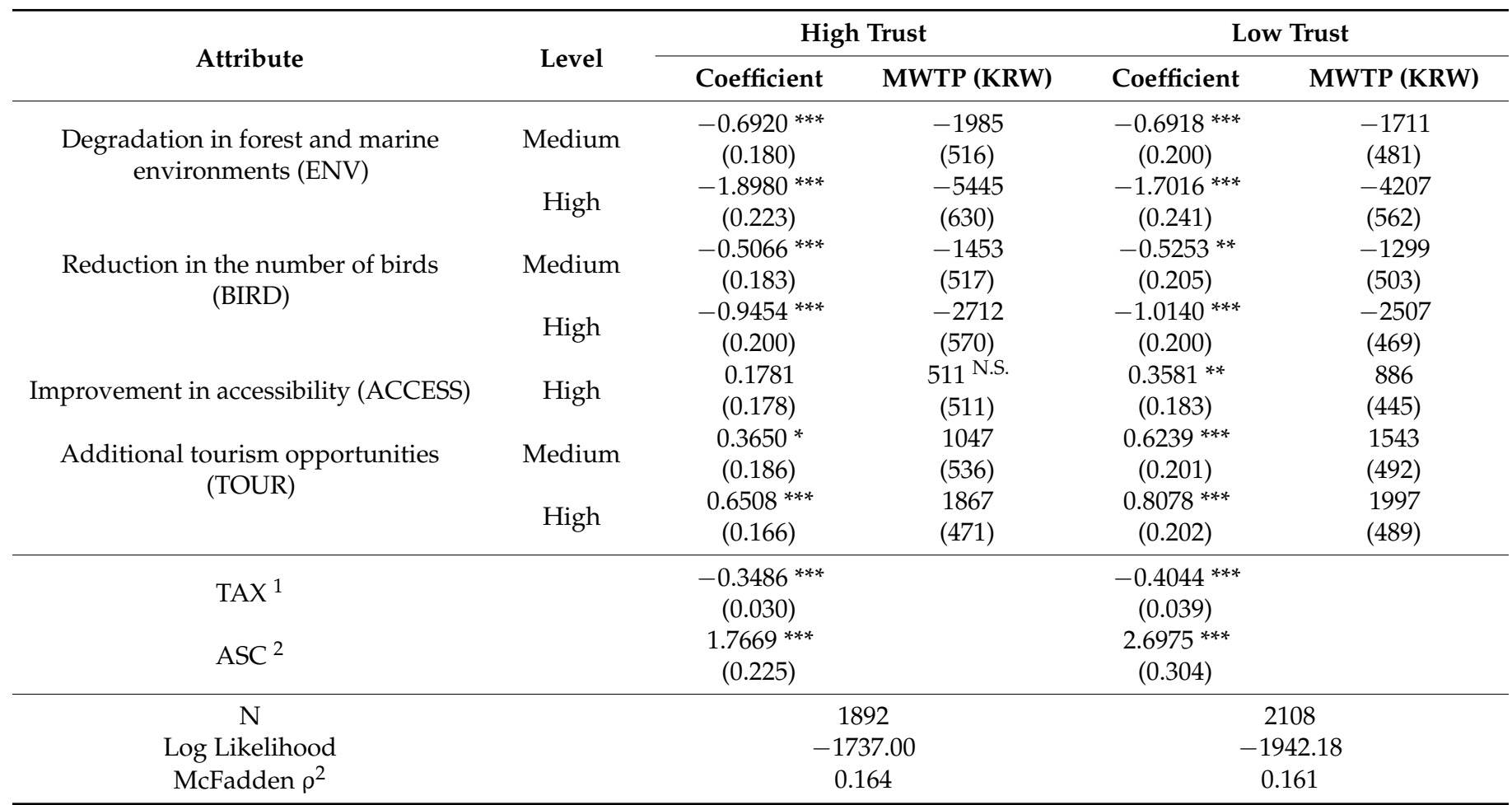

Note: Significance levels of $0.1,0.05$, and 0.01 are represented by $* * *$, and $* * *$, respectively. Standard errors in parentheses. N.S. $=$ nonsignificant coefficients. ${ }^{1}$ Tax/1000. ${ }^{2}$ The alternative specific constant (ASC) is coded 1 for alternative A and alternative B and 0 for neither alternative.

\section{Discussion and Conclusions}

This study assessed a major part of the economic costs and benefits derived from the construction of an airport in a national park. The DCE was employed to consider the tradeoffs between economic costs and benefits. Two attributes, ENV and BIRD, reflect economic costs, whereas ACCESS and TOUR belong to the economic benefits of the airport construction. The study results show that the environmental costs and economic benefits were estimated to be about KRW 7292 (USD 6.84) and KRW 2606 (USD 2.44), respectively, assuming that the levels changed from low (based on no change) to high (an utmost change derived from new airport construction). In addition, the two variables, VISIT and TRUST, were used for segmentation analysis to check for heterogeneous preferences among the segmented groups. Non-visitors indicated significantly higher economic costs of the airport construction, as measured by ENV and BIRD, than visitors did (KRW 7856 (USD 7.36) and KRW 5770 (USD 5.41), respectively). Regardless of the significance of coefficients, non-visitor reported, however, lower economic benefits, as measured by ACCESS and TOUR, than visitors did (KRW 3870 (USD 3.63) and KRW 2155 (USD 2.02), respectively). Similarly, the high-TRUST group reported higher economic costs (i.e., ENV and BIRD) than the low-TRUST group did (KRW 8157 (USD 7.65) and KRW 6714 (USD 6.29), respectively) but indicated lower economic benefits (ACCESS and TOUR) than their counterparts (KRW 2378 (USD 2.23) and KRW 2883 (USD 2.70), respectively). Thus, individuals who had visited the island and those with a low level of trust in the government's environmental policies were more supportive of the airport construction in Heuksando. These results suggest several policy-related implications.

First, the DCE results expectedly make the cost-benefit analysis of the airport construction project more comprehensive. The results show that a new airport would generate extensive economic benefits but that its economic costs could be also substantial. As indicated above, the attributes of ENV and BIRD can be considered the costs from the airport construction while ACCESS and TOUR can be considered its benefits. Thus, the total social 
costs were illustratively calculated using the total number of households in Korea, which is 19,673,875 [46]. The MWTPs at the population level amounted to KRW 91.6 billion (USD 85.8 million) for the ENV attribute and KRW 48.8 billion (USD 45.7 million) for BIRD, assuming that the levels changed from low to high. However, the sample of this study was limited to the visitors to the national parks and, thus, caution needs to be taken to generalize the results.

The KDI report [19], mentioned above, included only direct costs related to the construction and maintenance of the new airport and thus probably underestimated the costs, as environmental impacts were not properly considered. In brief, the report included reduced travel time as the primary social benefit, which amounted to KRW 33.7 billion (USD 31.6 million) based on an individual's value of reduced travel time (KRW 11,400 per hour as the opportunity cost of non-working time multiplied by $3 \mathrm{~h}$ for reduced travel time) and the number of plane users, who showed their interest in flying, among the visitors $(30 \%$ of $1,364,000)$ [19]. While reduced travel time is compatible with the attribute of ACCESS of this study, our results indicate that the equivalent benefits were estimated to be KRW 15.3 billion (USD 14.4 million) using the MWTP of ACCESS and the total number of households. This amount seems to be about half of the benefits projected by the KDI report [19], implying that the report likely overestimated the value of reduced travel time to support the airport construction. If environmental costs were properly included, the previous benefit-cost ratio at 4.38 [19] would be considerably lower.

Second, there are significant differences in economic value between the segmented groups based on previous experience visiting the island. Visitors placed higher economic values on BIRD and TOUR and a lower value on ENV than non-visitors did. This shows that visitors who are interested in having more tourism opportunities are concerned about a decrease in bird populations while non-visitors pay more attention to the negative environmental issues related to airport construction on the island. A similar result was found in Hearne and Salinas [55], where international tourists were found to be significantly in favor of preventing access to some of the ecotourism trails in order to reduce congestion and carrying capacity, while the results were not significant for the residents. Thus, visitors are more likely to be supportive of the airport construction than non-visitors. This finding can be interpreted as an example of the conflict paradigm suggested by Charles [56]. As stakeholders, the visitors seem to display a rationalization paradigm that favors user convenience and productivity while non-visitors lean more toward a conservation paradigm that prefers environmental conservation. Thus, the perspectives of both visitors and non-visitors should be taken into account when considering the airport construction in a national park. In addition, the results show that the coefficients of ACCESS were not significant for visitors or non-visitors, raising the question of whether the airport construction project would improve island accessibility, one of its main purposes.

Third, the results suggest that the degree of individuals' trust in the government's environmental policies influences their view on the development project. The high-TRUST group, that placed higher economic values on ENV and BIRD, was more concerned about environmental issues and was less interested in enjoying additional tourism opportunities with lower values on ACCESS and TOUR than the low-TRUST group. While this is seemingly counterintuitive, individuals' low trust in the government's environmental policies helps explain the results. The average for TRUST was 2.79, measured on a fivepoint Likert scale, indicating generally low trust in the government's environmental policy. In Grimmelikhuijsen et al.'s [53] comparative study, the mean values for the Korean sample were also generally lower than those of the Dutch sample. Trust may be low because the respondents are tired of various development projects such as the installation of cable cars in national parks and have learned that such development projects do not necessarily generate positive economic impacts and may even create a large deficit. The lack of transparency associated with public policy may also reduce the public's trust in the government [53]. Even those with a high level of trust in the government's environmental policies have more negative views (such as regarding the reduction in forests, coasts, and 
birds) than positive views (such as on the expansion of tourism opportunity and ease of access). These results suggest that the government needs to enhance public trust in its environmental policies. In other words, the government needs to be careful about proposing development projects that negatively affect the environment. Additionally, public education and outreach programs should be implemented to help stakeholders understand the goals and effects of government policies.

This study has several limitations that are worth noting for potential future research directions. First, the sample of this study was confined to those who had visited the national parks and did not include Heuksando residents. Preferences may differ between residents and nonresidents [39,57], and future research should examine if any preference heterogeneity exists between the two groups. Second, a decision rule such as majority rule [21] was not mentioned in the survey questionnaire based on the fact that policy decisions belong to more the political realm than public deliberation in Korea. Third, the two attributes associated with the benefits were expressed in qualitative terms, and the two other attributes associated with the costs were expressed in quantitative terms. Consequently, caution is needed in interpreting and generalizing the study results. Finally, there can be other factors that may not be easily quantifiable but important and the consequences of environmental damage may differ from those expected in the study design.

This study estimated a key part of the costs and benefits of the construction of Heuksan Airport using nonmarket valuation and showed how the preferences vary between the segmented groups. Regardless of the respondents' visit experience or level of trust in the government, they valued the environmental costs highly. The analytical framework used in this study can be also applicable to other development projects to assess tradeoffs between economic costs and benefits. Decision makers should consider the environmental costs tied to economic development when seeking stakeholders' preferred option between conservation and development.

Author Contributions: C.-O.O. designed the study and analyzed the data; M.K., C.-O.O., and S.L. wrote the original draft. All authors have read and agreed to the published version of the manuscript.

Funding: This research was funded under the project titled "Marine Ecosystem-Based Analysis and Decision Making Support System Development for Marine Spatial Planning" by the Ministry of Oceans and Fisheries (grant number 20170325).

Data Availability Statement: Data available on request due to privacy restrictions. The data presented in this study are available on request from the corresponding author.

Acknowledgments: We appreciate Soonjeong Kim of Yooshin Corporation and Ju Hyoung Han of Kangwon National University for their invaluable help during the data collection.

Conflicts of Interest: The authors declare no conflict of interest.

\section{Appendix A}

Heuksan airport was proposed to be constructed in Heuksando of Sinan County. This new airport is expected to help expand the tourism opportunities of park visitors to the Dadohae Marine National Park (DMNP) and to improve traffic accessibility for residents in the Heuksando area. Consequently, the airport will contribute to promoting economic development in the Heuksando area through nature tourism and to improving the quality of life for residents. On the other hand, the construction of the airport will inevitably cause various environmental concerns at the DMNP. In particular, as a result of securing airport runways and safety areas, $175,000 \mathrm{~m}^{2}$ of forests and 82,700 trees will be damaged and the number of migratory birds using the Heuksando area as a stopover point will decrease. Furthermore, additional environmental damage is anticipated, such as the reduction in habitats for flora and fauna, altercation of the coastline due to $85,600 \mathrm{~m}^{2}$ of coastal landfill, increases in water usage, and increases in household sewage and waste because of a growing number of tourists. 
Therefore, it is necessary to establish and implement plans that have both positive and negative impacts. Given the information above, we would like to ask how you evaluate the following choice sets, which consist of two alternatives and a no-choice option. You will be asked to choose a better alternative that you prefer in each choice set question.

\section{Appendix B}

Questions on the respondents' trust in the government's environmental policies proposed by Grimmelikhuijsen and Knies [53]:

I think that, when it concerns domestic environmental management policy,

a. The government is capable.

b. The government is effective.

c. The government is skillful.

d. The government is professional.

e. The government carries out its duty very well.

f. If citizens need help, the government will do its best to help them.

g. The government acts in the interest of citizens.

h. The government is genuinely interested in the well-being of citizens.

i. The government approaches citizens in a sincere way.

j. $\quad$ The government is sincere.

k. The government honors its commitments.

1. The government is honest.

\section{References}

1. McNeely, J.A. Protected areas for the 21st century: Working to provide benefits to society. Biodivers. Conserv. 1994, 3, $390-405$. [CrossRef]

2. Spenceley, A.; Goodwin, H. Nature-based tourism and poverty alleviation: Impacts of private sector and parastatal enter-prises in and around Kruger National Park, South Africa. Curr. Issues Tour. 2007, 10, 255-277. [CrossRef]

3. Halpern, B.S.; Walbridge, S.; Selkoe, K.A.; Kappel, C.V.; Micheli, F.; D’Agrosa, C.; Bruno, J.F.; Casey, K.S.; Ebert, C.; Fox, H.E.; et al. A Global Map of Human Impact on Marine Ecosystems. Science 2008, 319, 948-952. [CrossRef] [PubMed]

4. Lester, S.E.; Halpern, B.S.; Grorud-Colvert, K.; Lubchenco, J.; Ruttenberg, B.I.; Gaines, S.D.; Airamé, S.; Warner, R.R. Biologi-cal effects within no-take marine reserves: A global synthesis. Mar. Ecol. Prog. Ser. 2009, 384, 33-46. [CrossRef]

5. Leverington, F.; Costa, K.L.; Pavese, H.; Lisle, A.; Hockings, M. A global analysis of protected area management effective-ness. Environ. Manag. 2010, 46, 685-698. [CrossRef]

6. Brown, K.; Adger, W.N.; Tompkins, E.; Bacon, P.; Shim, D.; Young, K. Trade-off analysis for marine protected area man-agement. Ecol. Econ. 2001, 37, 417-434. [CrossRef]

7. Mankiw, N.G. Principles of Microeconomics, 8th ed.; Cenegage Learning: Boston, MA, USA, 2008.

8. Bass, M.S.; Finer, M.; Jenkins, C.N.; Kreft, H.; Cisneros-Heredia, D.F.; McCracken, S.F.; Pitman, N.C.A.; English, P.H.; Swing, K.; Villa, G.; et al. Global Conservation Significance of Ecuador's Yasuní National Park. PLoS ONE 2010, 5, e8767. [CrossRef]

9. Alpizar, F.; Carlsson, F.; Martinsson, P. Using choice experiments for non-market valuation. Econ. Issues 2001, 8, 83-110.

10. Mitchell, R.C.; Carson, R.T. Using Surveys to Value Public Goods: The Contingent Valuation Method; The Johns Hopkins University Press: Washington, DC, USA, 1989.

11. Christie, P. Marine protected areas as biological successes and social failures in Southeast Asia. Am. Fish. Soc. Symp. 2004, 2004, 155-164.

12. Dehens, L.A.; Fanning, L. What counts in making marine protected areas (MPAs) count? The role of legitimacy in MPA success in Canada. Ecol. Indic. 2018, 86, 45-57. [CrossRef]

13. Minteer, B.A.; Miller, T.R. The New Conservation Debate: Ethical foundations, strategic trade-offs, and policy opportunities. Biol. Conserv. 2011, 144, 945-947. [CrossRef]

14. McShane, T.O.; Hirsch, P.D.; Trung, T.C.; Songorwa, A.N.; Kinzig, A.; Monteferri, B.; Mutekanga, D.; Van Thang, H.; Dammert, J.L.; Pulgar-Vidal, M.; et al. Hard choices: Making trade-offs between biodiversity conservation and human well-being. Biol. Conserv. 2011, 144, 966-972. [CrossRef]

15. Joppa, L.N.; Pfaff, A. Global protected area impacts. Proc. R. Soc. B Boil. Sci. 2010, 278, 1633-1638. [CrossRef] [PubMed]

16. Mascia, M.B.; Pailler, S. Protected area downgrading, downsizing, and degazettement (PADDD) and its conservation impli-cations. Conserv. Lett. 2011, 4, 9-20. [CrossRef]

17. Tesfaw, A.T.; Pfaff, A.; Kroner, R.E.G.; Qin, S.; Medeiros, R.; Mascia, M.B. Land-use and land-cover change shape the sustainability and impacts of protected areas. Proc. Natl. Acad. Sci. USA 2018, 115, 2084-2089. [CrossRef] 
18. Kroner, R.E.G.; Qin, S.; Cook, C.N.; Krithivasan, R.; Pack, S.M.; Bonilla, O.D.; Cort-Kansinally, K.A.; Coutinho, B.; Feng, M.; Garcia, M.I.M.; et al. The uncertain future of protected lands and waters. Science 2019, 364, 881-886. [CrossRef]

19. KDI (Korea Development Institute). Heuksando Airport Construction Project: Pre-Feasibility Report; KDI: Seoul, Korea, 2013.

20. Alexander, K.; Ramotadima, M.; Sanderson, C.E. The power of consensus: Developing a community voice in land use planning and tourism development in biodiversity hotspots. Ecosyst. Serv. 2018, 30, 350-361. [CrossRef]

21. Johnston, R.J.; Boyle, K.J.; Adamowicz, W.; Bennett, J.; Brouwer, R.; Cameron, T.A.; Hanemann, W.M.; Hanley, N.; Ryan, M.; Scarpa, R.; et al. Contemporary Guidance for Stated Preference Studies. J. Assoc. Environ. Resour. Econ. 2017, 4, 319-405. [CrossRef]

22. KNPS (Korea National Park Service). 2018 National Parks Basic Statistics; KNPS: Wonju, Korea, 2018.

23. Chang, H. Reinterpreting a public conflict over development and environmental conservation: A conflict in national park ropeway project through the advocacy coalition framework and the conflict cycle model (in Korean). Korean J. Policy Anal. Eval. 2019, 29, 57-88.

24. Lee, M.S.; Choi, Y.B.; Yoon, S.W.; Kwak, D.H.; Shin, S.C. A comparative study on the national park management (in Korean). J. Nat. Sci. Joongbu Univ. 2001, 10, 47-55.

25. Kim, M.-H.; Kwon, H.-G.; Han, S.-Y. Trends of national park management policy paradigm using the newspaper editorials (in Korean). J. Korean Inst. For. Recreat. 2013, 17, 31-36.

26. Yeo, E. Study on the legal regime of national parks in France and Korea (in Korean). J. Law Polit. Res. 2017, 17, 339-366.

27. Hwang, J.-T.; Park, B.-G. Seeing the state-nature relation in South Korea from the perspective of political ecology. J. Korean Geogr. Soc. 2013, 48, 348-365. (In Korean)

28. Kim, S. Public Trust in Government in Japan and South Korea: Does the Rise of Critical Citizens Matter? Public Adm. Rev. 2010, 70, 801-810. [CrossRef]

29. Hanley, N.; Wright, R.E.; Adamowicz, V. Using choice experiments to value the environment: Design issues, current expe-rience and future prospects. Environ. Resour. Econ. 1998, 11, 413-428. [CrossRef]

30. Hoyos, D. The state of the art of environmental valuation with discrete choice experiments. Ecol. Econ. 2010, 69, 1595-1603. [CrossRef]

31. Kanninen, B.J. Valuing Environmental Amenities Using Stated Choice Studies: A Common Sense Approach to Theory and Practice; Springer: Dordrect, The Netherlands, 2007.

32. Adamowicz, W.; Boxall, P.; Williams, M.; Louviere, J. Stated Preference Approaches for Measuring Passive Use Values: Choice Experiments and Contingent Valuation. Am. J. Agric. Econ. 1998, 80, 64-75. [CrossRef]

33. Lehtonen, E.; Kuuluvainen, J.; Pouta, E.; Rekola, M.; Li, C.-Z. Non-market benefits of forest conservation in southern Finland. Environ. Sci. Policy 2003, 6, 195-204. [CrossRef]

34. Nielsen, A.B.; Olsen, S.B.; Lundhede, T. An economic valuation of the recreational benefits associated with nature-based forest management practices. Landsc. Urban. Plan. 2007, 80, 63-71. [CrossRef]

35. Chaminuka, P.; Groeneveld, R.A.; Selomane, A.O.; van Ierland, E.C. Tourist preferences for ecotourism in rural communi-ties adjacent to Kruger National Park: A choice experiment approach. Tour. Manag. 2012, 33, 168-176. [CrossRef]

36. Scarpa, R.; Thiene, M.; Hensher, D.A. Monitoring Choice Task Attribute Attendance in Nonmarket Valuation of Multiple Park Management Services: Does It Matter? Land Econ. 2010, 86, 817-839. [CrossRef]

37. Carlsson, F.; Frykblom, P.; Liljenstolpe, C. Valuing wetland attributes: An application of choice experiments. Ecol. Econ. 2003, 47, 95-103. [CrossRef]

38. McVittie, A.; Moran, D. Valuing the non-use benefits of marine conservation zones: An application to the UK Marine Bill. Ecol. Econ. 2010, 70, 413-424. [CrossRef]

39. Oh, C.-O.; Draper, J.; Dixon, A.W. Comparing resident and tourist preferences for public beach access and related amenities. Ocean. Coast. Manag. 2010, 53, 245-251. [CrossRef]

40. Biénabe, E.; Hearne, R.R. Public preferences for biodiversity conservation and scenic beauty within a framework of envi-ronmental services payments. For. Policy Econ. 2006, 9, 335-348. [CrossRef]

41. KNPS (Korea National Park Service). Available online: http:/ / english.knps.or.kr/ (accessed on 4 February 2020).

42. Yong, D.L.; Liu, Y.; Low, B.W.; Española, C.P.; Choi, C.-Y.; Kawakami, K. Migratory songbirds in the East Asian-Australasian Flyway: A review from a conservation perspective. Bird Conserv. Int. 2015, 25, 1-37. [CrossRef]

43. Park, C.; Seo, S.-G.; Lee, S.-Y.; Cho, S.-Y.; Park, S.-Y.; Kwon, Y.-S. Bird status of Heuksan-do(Is.), Dadohaehaesang National Park in Korea. J. Natl. Park Res. 2014, 5, 130-142. (In Korean)

44. Won, I.-J.; Park, J.-G.; Hong, G.-P.; Kim, S.-J.; Choi, C.-Y.; Bing, G.-C.; Nam, H.-Y.; Chae, H.-Y. Migratory Patterns of Birds on Hongdo and Heuksando Islands. J. Natl. Park Res. 2009, 1, 29-44. (In Korean)

45. Sinan County. Available online: http://www.shinan.go.kr/home/www/about/current_sta (accessed on 17 December 2017).

46. Statistics Korea. Available online: http:/ / kosis.kr/eng/ (accessed on 4 February 2020).

47. Yooshin Corporation. Environmental Impact Assessment of Heuksan Airport Construction Project (Draft); Yooshin Corporation: Seoul, South Korea, 2016. (In Korean)

48. Kuhfeld, W.F. Experimental Design, Efficiency, Coding, and Choice Designs. 2005, pp. 53-241. Available online: http://support. sas.com/techsup/technote/mr2010c.sas (accessed on 3 February 2021).

49. Manski, C.F. The structure of random utility models. Theory Decis. 1977, 8, 229-254. [CrossRef] 
50. Ben-Akiva, M.E.; Lerman, S.R. Discrete Choice Analysis: Theory and Application to Travel Demand; MIT Press: Cambridge, MA, USA, 1985.

51. McFadden, D. The measurement of urban travel demand. J. Public Econ. 1974, 3, 303-328. [CrossRef]

52. Train, K.E. Discrete Choice Methods with Simulation, 2nd ed.; Cambridge University Press: Cambridge, UK, 2009.

53. Grimmelikhuijsen, S.; Porumbescu, G.; Hong, B.; Im, T. The effect of transparency on trust in government: A cross-national comparative experiment. Public Adm. Rev. 2013, 73, 575-586. [CrossRef]

54. Greene, W.H. Econometric Analysis; Prentice Hall: Upper Saddle River, NJ, USA, 2000.

55. Hearne, R.R.; Salinas, Z.M. The use of choice experiments in the analysis of tourist preferences for ecotourism development in Costa Rica. J. Environ. Manag. 2002, 65, 153-163. [CrossRef] [PubMed]

56. Charles, A.T. Fishery conflicts: A unified framework. Mar. Policy 1992, 16, 379-393. [CrossRef]

57. Kim, J.-Y.; Mjelde, J.W.; Kim, T.-K.; Lee, C.-K.; Ahn, K.-M. Comparing willingness-to-pay between residents and non-residents when correcting hypothetical bias: Case of endangered spotted seal in South Korea. Ecol. Econ. 2012, 78, 123-131. [CrossRef] 